Boise State University

ScholarWorks

Geosciences Faculty Publications and

Presentations

Department of Geosciences

$5-2015$

\title{
Seismic Imaging to Help Understand and Manage Water Quality in Coastal Bénin, West Africa
}

Kyle Lindsay

Boise State University

John Bradford

Boise State University

Steve Silliman

Gonzaga University

Nicaise Yalo

Université d'Abomey-Calavi

Moussa Boukari

Université d'Abomey-Calavi

This is an author-produced, peer-reviewed version of this article. The final, definitive version of this document can be found online at Geophysics, published by the Society of Exploration Geophysicists. Copyright restrictions may apply. doi: 10.1190/geo2014-0115.1 


\title{
Seismic imaging to help understand and manage water quality in coastal Bénin, West Africa
}

\author{
Kyle Lindsay ${ }^{1}$, John Bradford ${ }^{1}$, Stephen Silliman ${ }^{2}$, Nicaise Yalo ${ }^{3}$, and Moussa Boukari ${ }^{3}$
}

\begin{abstract}
We collected seismic data along 15 transects to characterize the geometry of a coastal aquifer in Bénin, West Africa, that is being contaminated by saltwater. We used standard high-resolution seismic methods to image the upper $\sim 200 \mathrm{~m}$ using a sledgehammer source and a 120-channel recording system. Three transects were processed with an iterative updating flow that includes prestack depth migration, residual moveout analysis, and reflection tomography, and the remaining 12 transects were processed with routine processing flows and poststack time migration. We identified one unconfined aquifer and three confined aquifers separated by reflective confining clay layers. Some transects showed areas of missing reflectors, which we interpreted as sand-filled channels that could provide potential highpermeability conduits for saltwater flow to the Godomey well field.
\end{abstract}

\section{INTRODUCTION}

Coastal groundwater resources are a critical component of available freshwater for coastal cities around the world. Rising population density in many of these areas has resulted in overextraction of groundwater resources, leading to saltwater intrusion into freshwater aquifers (Bray et al., 2007; Vandenbohede et al., 2009; Werner, 2010; Silliman et al., 2011). This problem is especially prevalent in developing countries where it is difficult to assess and manage water resources due to lack of money, government resource management programs, and technical resources. One such area is the coastal city of Cotonou, Bénin, in West Africa.
Cotonou is Bénin's largest city with a population of 1.5-2.0 million people and lies in the southeast of the country along the Atlantic Coast (Figure 1a). The sole source of drinking water for Cotonou is the Godomey aquifer, which is currently undergoing saltwater intrusion (Silliman et al., 2010). Currently, the annual rate of urbanization in Bénin is approximately $4 \%$. The growth of the urban population has necessitated an increase in the pumping rate from the city's primary well field, known as the Godomey well field. The Godomey well field lies roughly $5 \mathrm{~km}$ north of the Atlantic Ocean and is bordered on the east by Lake Nokoué, a large saltwater lake connected to the Atlantic Ocean via a canal (Figure 1a). The well field consists of more than 20 wells (Figure 1b), which withdraw water from one or more of three confined aquifers ranging in depth from 30 to $150 \mathrm{~m}$ (Figure 1c).

The pumping rate in the Godomey well field has increased steadily on average by about $900,000 \mathrm{~m}^{3} / \mathrm{yr} / \mathrm{yr}$ from 1990 to 2005 (Figure 2). The increased pumping rate has been accommodated by adding new wells at progressively increasing distances from Lake Nokoué (Silliman et al., 2010). Increased pumping has been accompanied by an increase in salinity in the wells in the eastern portion of the well field, closest to the lake (Figure 2). Since 2001, four wells (F2, F4, F6, and F8 in Figure 1b) on the eastern portion of the Godomey well field have been abandoned due to saltwater intrusion (Boukari et al., 2008).

The two potential sources of salinity in the well field are the Atlantic Ocean and Lake Nokoué. However, previous studies by Silliman et al. (2010) show that wells closest to the ocean give no indication of increased salinity in the deeper aquifers, indicating that saltwater intrusion directly from the Atlantic Ocean is currently not a threat to the Godomey well field. All of the wells showing increased salinity are close to Lake Nokoué. Additionally, initial hydrologic models indicate that there is a groundwater divide between the Atlantic Ocean and the Godomey well field due to a

First presented at the SEG 83rd Annual International Meeting. Manuscript received by the Editor 7 March 2014; revised manuscript received 20 August 2014 ; published online 23 April 2015.

${ }^{1}$ Boise State University, Center for Geophysical Investigation of the Shallow Subsurface (CGISS), Boise, Idaho, USA. E-mail: kylelindsay @u.boisestate.edu; jbradfor@boisestate.edu.

${ }^{2}$ Gonzaga University, School of Engineering and Applied Science, Spokane, Washington, USA. E-mail: Silliman@gonzaga.edu.

${ }^{3}$ Université d'Abomey-Calavi, Départment des Sciences de la Terre, Bénin, West Africa. E-mail: yalonicaise@yahoo.fr; moussaboukari2003@yahoo.fr.

(C) 2015 Society of Exploration Geophysicists. All rights reserved. 
topographic high that parallels the coast and that Lake Nokoue is the likely source of salinity (Boukari et al., 2008). These models predict that increased pumping will result in greater recharge being

a)

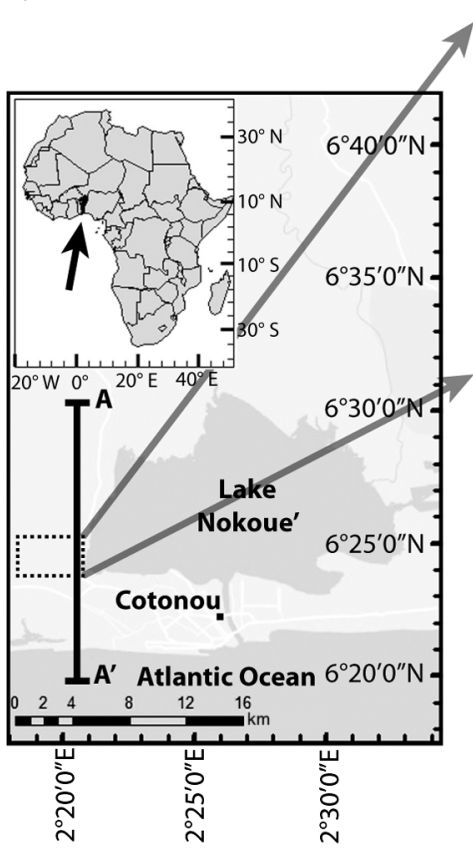

b)

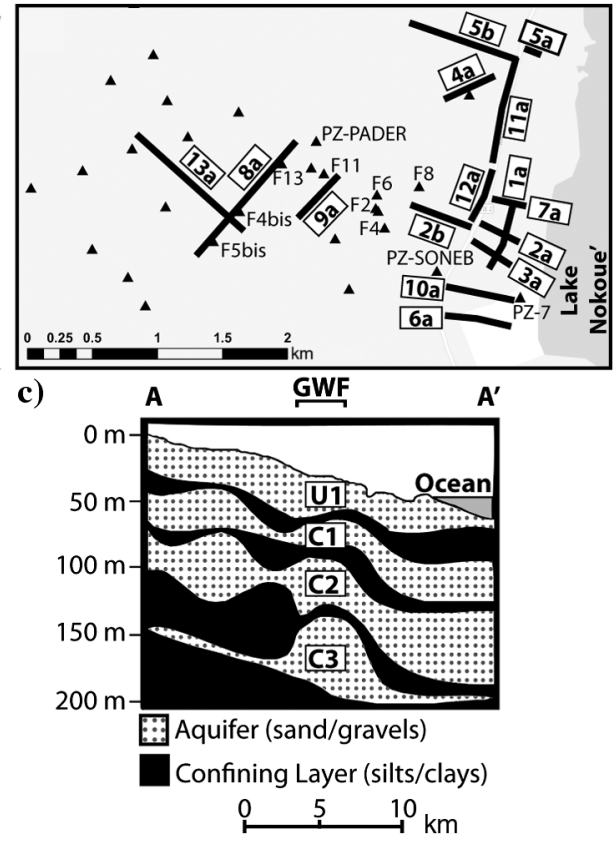

Figure 1. (a) Inset map of Africa highlighting the location of Bénin, shown in black with an arrow and the regional map of coastal Bénin representing the study area. The Godomey well field is located in the dashed box. (b) Map of the Godomey well field showing the location of the 15 seismic profiles (black lines) acquired along with the location of wells and piezometers (triangles) in the area. Wells and piezometers discussed in this paper are labeled with prefix $\mathrm{F}$ for the wells and prefix PZ for piezometers. (c) Schematic cross section of the regional geology along transect A-A' (Figure 1a). GWF represents the location of the Godomey well field. The geology of the well field comprises an unconfined sand aquifer (U1) and three confined sand/gravel aquifers (C1, C2, and C3). The confining layers comprise silts and clays (modified from Silliman et al., 2010).

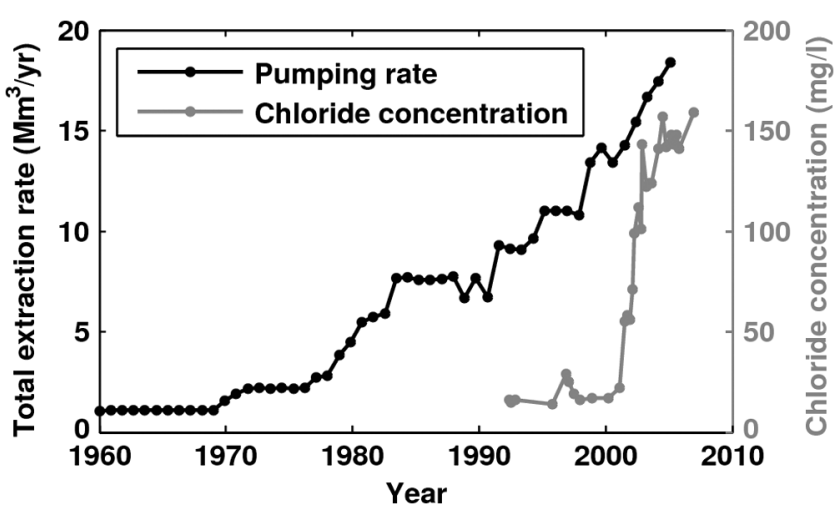

Figure 2. Evolution of the pumping rate in the Godomey well field (black) and chloride concentration in well F11 (gray). Yearly extraction rates were calculated by summing monthly pumping averages based on detailed registration of active pump hours and the corresponding amount of water pumped for all major extraction wells. The pumping rate of the Godomey well field has increased on average by about $900,000 \mathrm{~m}^{3} / \mathrm{yr} / \mathrm{yr}$ since 1990 , and has been accompanied by a rapid increase in chloride concentration beginning in the year 2000 derived from the western part of Lake Nokoué, consistent with observations of increased salinity in wells closest to the lake (Silliman et al., 2010).

Although initial hydrologic models provide general information about the aquifer system, they are not yet at the stage of a quantitative management tool in which data-driven management decisions can be made. In particular, challenges remain in the modeling effort in terms of tempo$\mathrm{ral} / \mathrm{spatial}$ distribution of hydraulic head. The aquifer geometry of the current hydrologic model is based on analysis of well log data that is limited by the areal extent of the wells in the well field. There have been no wells drilled in Lake Nokoué. Consequently, little is known about the geology underlying the lake and how it is connected to the geology in the well field.

One of the key characterization needs identified by Silliman et al. (2010) is mapping of the primary water-bearing units to better understand and quantify the lateral continuity of flow paths. Quantifying the continuity of these units is necessary to improve the spatial resolution of the current hydrologic model and determine transport pathways between the recharge areas in Lake Nokoué and the Godomey well field.

In studies of the coastal plain environment, numerous authors have demonstrated the success of geophysical surveys applied to saltwater intrusion problems (Yang et al., 1999; Shtivelman and Goldman, 2000; Sumanovac, 2006; Nguyen et al., 2009). Shallow reflection seismology is a technique well suited to determining the lateral continuity of hydrostratigraphic units in the Godomey well field. To investigate the continuity of water transport pathways between the lake and the Godomey well field, we collected seismic data along 15 transects around the southwest coast of Lake Nokoué. In this paper, we first describe the acquisition and processing of our seismic data. Second, we present the results from our seismic campaign and discuss the potential impact they have on the hydrologic model for the Godomey aquifer.

\section{HYDROGEOLOGIC SETTING}

The Godomey well field lies on the southeastern portion of the Plateau of Allada, in the coastal sedimentary basin of Bénin. The geology of the sedimentary basin has been previously described by multiple authors (Blivi et al., 2002; Barthel et al., 2008, 2009; Boukari et al., 2008) and is composed of three primary lithologic units consisting of a Pleistocene clayey-sand, Pliocene sandy-clay, and Miocene sand (Boukari et al., 2008). These layers make up the coastal aquifer system and rest in angular unconformity on a highly heterogeneous Eocene clay/marl substratum at a depth of 180-220 m.

The geology in the zone of production is composed of interbedded sands, silts, and clays that form four primary aquifers separated by confining clay layers (Figure 1c). For the remainder of this paper, we will refer to the four aquifers as $\mathrm{U} 1, \mathrm{C} 1, \mathrm{C} 2$, and $\mathrm{C} 3$, where $\mathrm{U} 1$ is the top unconfined aquifer and $\mathrm{C} 1, \mathrm{C} 2$, and $\mathrm{C} 3$ are 
the three confined aquifers in order of increasing depth (Figure 1c). Thicknesses range from 10 to $50 \mathrm{~m}$ for sand units and from 5 to $10 \mathrm{~m}$ for confining clay layers. The lithology dips slightly to the south, with several of the deeper aquifer units extending beneath the Atlantic Ocean, potentially exposing them to saltwater influx from the Atlantic Ocean due to excessive groundwater pumping.

Lake Nokoué is dynamic in terms of its hydraulics and water quality. Field data (water levels and measures of specific conductance in the lake and groundwater) suggest active interaction of the lake with river inflows from the north, the ocean to the south (via an open channel connecting the lake to the ocean), and the groundwater system. Specifically, during periods of low precipitation, there is strong similarity in water-level variations observed in the lake and in wells within the region of the Godomey well field. These periods are accompanied by active exchange between the lake and ocean via the channel connecting the lake to the ocean and increasing conductivity in the lake to a maximum (dependent on location in the lake) between $50 \%$ and $100 \%$ of the conductivity (salinity) of the ocean water. In contrast, periods of heavy precipitation are accompanied by an increase in the water level in the lake disproportionate with water level increase observed in the groundwater. Further, water inflow via rivers during periods of precipitation results in flushing of salinity from the lake. The southwestern region of the lake (the region closest to the well field) shows elevated conductance (salinity) even during periods in which the lake water is elevated following precipitation, suggesting this region of the lake as a possible region of recharge to the groundwater immediately east of the Godomey well field with water containing elevated salinity.

\section{SEISMIC REFLECTION DATA}

\section{Acquisition}

Seismic data were collected along 15 transects during two field seasons for a total of approximately $9 \mathrm{~km}$ of reflection data (Figure 1b). The study site is located in a large urban center where logistic obstacles and high levels of cultural noise made many preferred survey sites either inaccessible or unfit for collecting high-quality data. Seismic profiles were chosen based on the above logistic considerations and research objectives. Seismic acquisition was focused on the eastern side of the Godomey well field to investigate the lateral continuity of hydrostratigraphic units between Lake Nokoué and the well field. We also collected data along two transects located near the center of the well field that are adjacent to production wells.

Survey design parameters were chosen based on the primary objective of obtaining a high-resolution image of the Godomey aquifer system $(<250 \mathrm{~m}$ depth) and are given in Table 1. Despite the noisy urban environment, surface conditions provided excellent source and receiver coupling resulting in data with a high signal-to-noise ratio as evidenced in Figure 3.

\section{Processing}

We processed all lines with a routine processing flow with the exceptions of lines 5b, 8a, and 10a (Figure 4). Although most of the reflectors in the other 12 lines are approximately horizontal, as will be shown, these three lines contain stratigraphic complexity. Imaging and positioning problems are intrinsic to poststack migra- tion methods due to the assumptions of NMO processing, namely, hyperbolic moveout and small lateral and vertical velocity variations. Because lines 5b, 8a, and 10a exhibit structural complexity, we chose to use reflection tomography in the postmigration domain using the method of Stork (1992) to improve velocity and image accuracy to better constrain interpretation.

\section{Simple processing flow}

The lines closest to the lake were processed using the simple processing flow shown in Figure 4. Because the data show some scattering of energy, we applied poststack time migration to the

Table 1. Survey and recording parameters.

Recording instrument Geometrics, 24-bit, 120-channel seismograph

Receiver array 10-Hz vertical geophones

Source

Geometry

Receiver spacing 10-kg sledgehammer

Source spacing

Number of geophones

Inline

Sampling interval

$3 \mathrm{~m}$ (lines 1-11), $5 \mathrm{~m}$ (lines 12-13)

$6 \mathrm{~m}$ (lines 1-11), $5 \mathrm{~m}$ (lines 12-13) 48-96

Record length

$0.5 \mathrm{~ms}$

Record stacks

5

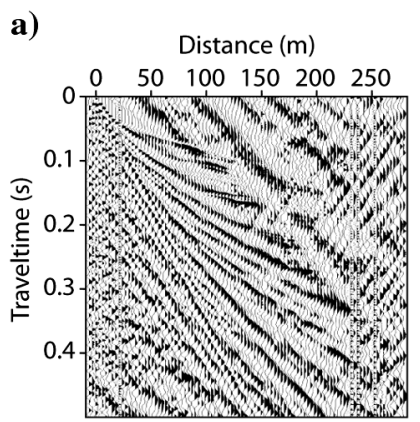

c)

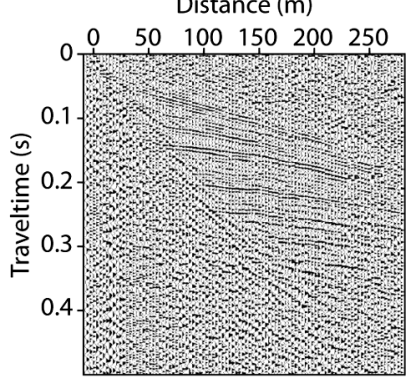

b)

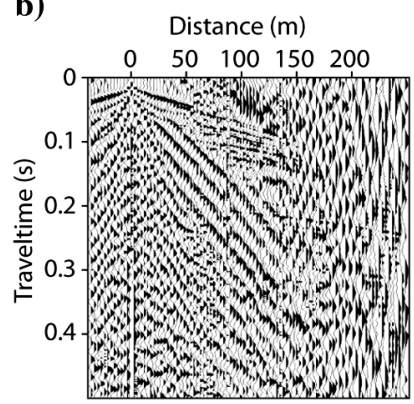

d)

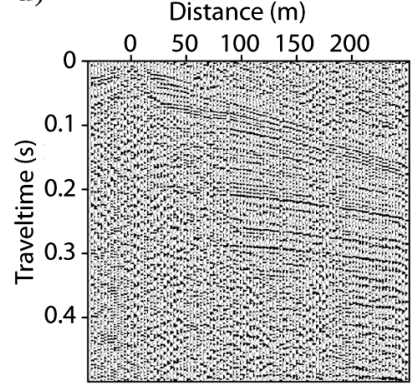

Figure 3. ( $a$ and b) Raw shot gathers with AGC applied (50-ms window) from lines $5 \mathrm{~b}$ and $6 \mathrm{a}$, respectively (Figure $1 \mathrm{~b}$ ). (c and d) The same shots with spectral whitening (40-60-200-300 Hz) and AGC applied (50 ms window). Note that the simple spectral whitening filter was extremely effective in removing high-amplitude ground roll and traffic noise. 
common depth point (CDP) stacked seismic profiles. We used a phase-shift migration algorithm based on the method of Gazdag (1978) with a maximum migration frequency of $300 \mathrm{~Hz}$ and maximum dip angle of $90^{\circ}$. To derive the migration velocity models, we converted the smoothed stacking velocities to time-interval velocity models via a smoothed gradient method. The smoothed gradient method produces a smoothed time-interval velocity model using the Dix equation and cubic spline interpolation. The smoothed time-interval velocities were used to convert the profiles to depth.

Because of the high levels of cultural noise, we did not attempt true amplitude processing and applied automatic gain control (AGC) early in our processing flow to enhance reflection signal. To accurately compare depths between different seismic profiles, all profiles were moved to a final datum elevation of $43 \mathrm{~m}$. This datum is the highest elevation of all 15 seismic lines and is located on line 8 a near the center of the well field and was chosen due to the shallow water table. We completed all processing steps using Pro$\mathrm{MAX}^{\mathrm{TM}}$ data processing software. This simple processing flow produced high-quality stacked images with relatively flat-lying reflectors (Figure 5).

\section{Reflection tomography}

The modeling flow adopted for this work is based on an iterative updating procedure for refining an initial depth-velocity model, consisting of prestack depth migration (PSDM), residual moveout

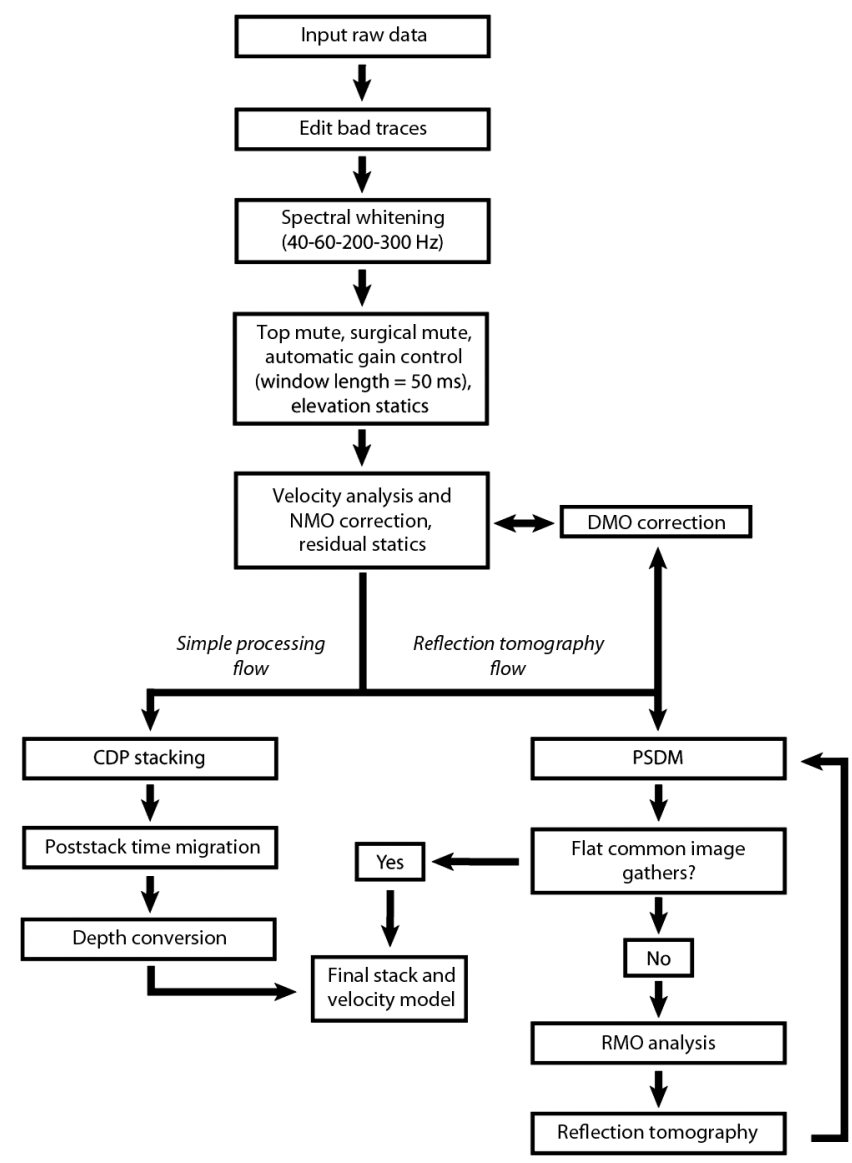

Figure 4. Processing flowchart for the simple processing flow and the reflection tomography flow applied to lines $5 \mathrm{~b}, 8 \mathrm{a}$, and $10 \mathrm{a}$. analysis (RMO), and reflection tomography. PSDM combined with RMO analysis and reflection tomography is common practice in the oil and gas industry and is becoming increasingly used in the shallow near-surface environment (Bradford, 2002; Bradford and Sawyer, 2002; Guo and Fagin, 2002a, 2002b; Bradford et al., 2006; Giustiani et al., 2009). RMO analysis is applied to common image gathers that have been output from a prestack migration algorithm, and it operates in the same way as conventional velocity analysis. If the migration velocity is correct, the reflection event on the gather will be flat. If the migration velocity is incorrect, the reflection event is overcorrected or undercorrected, and the remaining moveout is used as input to the reflection tomography to generate a corrected velocity model. At each iteration, velocities and reflector horizons are updated until reflectors on common image gathers are flat lying (Stork, 1992).

Preprocessing migration steps for lines 5b, 8a, and 10a were identical to the previous 12 lines up to velocity analysis (Figure 4). To derive starting depth-velocity intervals, we applied a dip moveout correction (DMO) prior to velocity analysis. We then converted the smoothed stacking velocities to depth-velocity models. We used a Kirchhoff migration method in the common offset domain and migrated the data from topography with a maximum frequency of $300 \mathrm{~Hz}$ and maximum migration aperture set to half the length of a spread. After two iterations of reflection tomography, there were no significant changes in velocity models and reflectors were sufficiently flat. The PSDM images and final velocity models for lines 5b, 8a, and 10a are shown in Figure 6.

\section{RESULTS}

We identified three distinct velocity zones from our tomographic inversion results that correlate with the top unconfined aquifer, the three confined aquifers, and the clay/marl base (Figure 6). Based on correlation with well logs from the area, we interpret the prominent reflections as originating from the transitions from sand aquifers to confining clay layers (Figure $6 \mathrm{~d}$ and $6 \mathrm{f}$ ). The strong reflection at $\sim 200 \mathrm{~m}$ depth is seen on all 15 profiles and is interpreted as originating from the transition from aquifer $\mathrm{C} 3$ to the clay/marl base. This interpretation is consistent with geologic data and the velocity increase from 1900 to $2100 \mathrm{~m} / \mathrm{s}$ (Figure 6). The dominant frequency of the reflections is about $80 \mathrm{~Hz}$. Taking the average veloc-

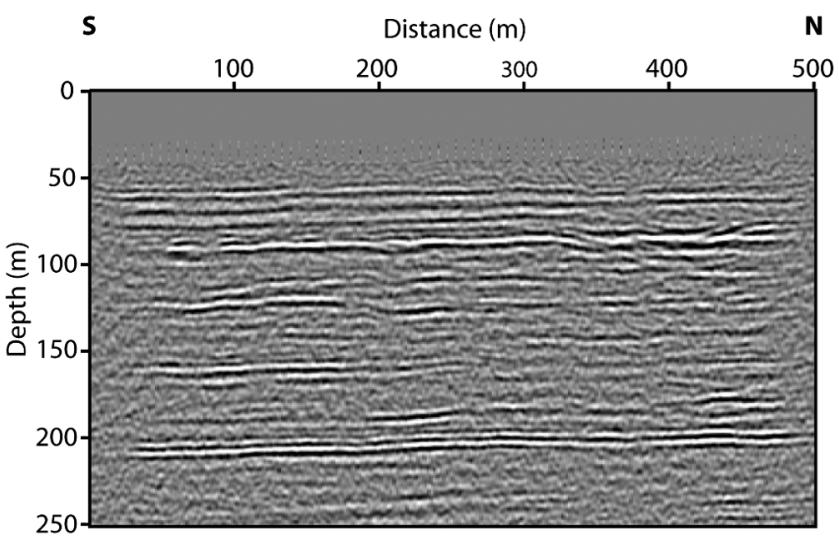

Figure 5. Final stacked profile of line 1a (Figure 1b) obtained by applying the simple processing flow described in the text and shown in Figure 4. All reflectors are horizontal with a slight dip $\left(\sim 1^{\circ}-2^{\circ}\right)$ to the south. 
ity of sediments in our study area to be $1800 \mathrm{~m} / \mathrm{s}$ gives a dominant wavelength of $22.5 \mathrm{~m}$. For clarity, when we refer to depth, we are referring to depth below the datum elevation.

\section{Line 5b}

Line 5b (Figure 6a and 6b) shows most clearly the general hydrostratigraphy of the study area with the four primary aquifer units easily distinguished by the laterally continuous reflections. We interpret two channel features within the upper two aquifer units that extend from 50 to $300 \mathrm{~m}$ distance and $400 \mathrm{~m}$ to the end of the line (yellow dashed lines in Figure 6b). This interpretation is based on the reflector geometry and low-velocity zones located in the axes of these channels. The two high-amplitude reflections beneath each of the channels at $\sim 75 \mathrm{~m}$ depth (red dashed lines Figure $6 \mathrm{~b}$ ) have similar geometries to the overlying channels and are interpreted as older channel deposits in a stacked paleochannel sequence.

\section{Line 8a}

Line 8a (Figure 6c, and d) is located near the center of the Godomey well field and runs adjacent to production wells F13, F4bis, a)

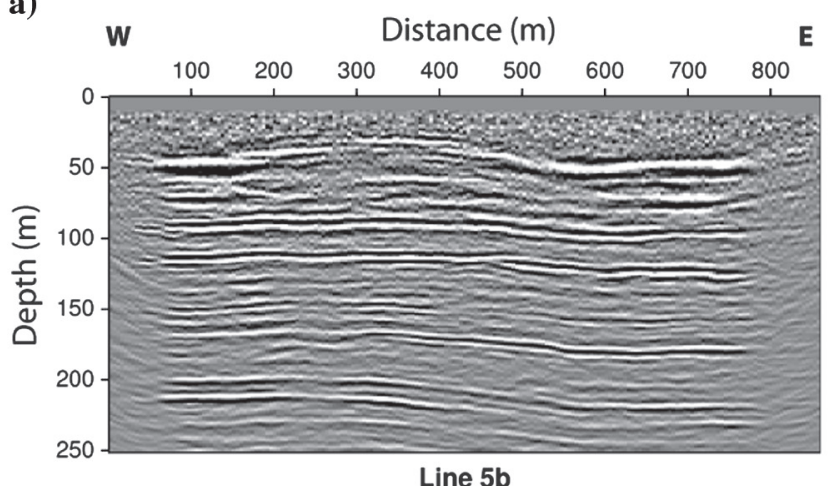

b)

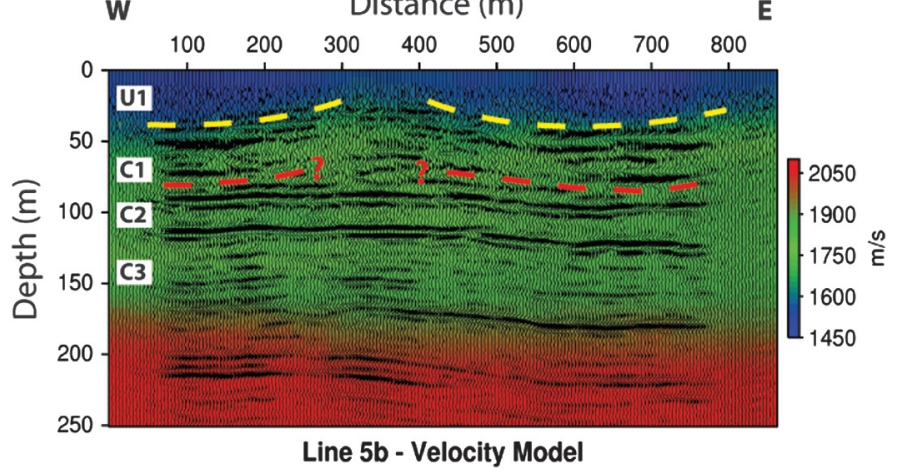

d)

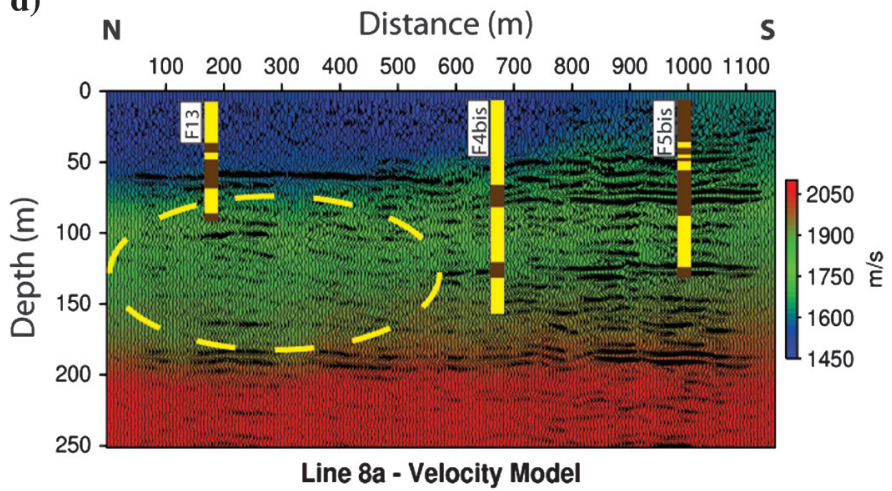

f)

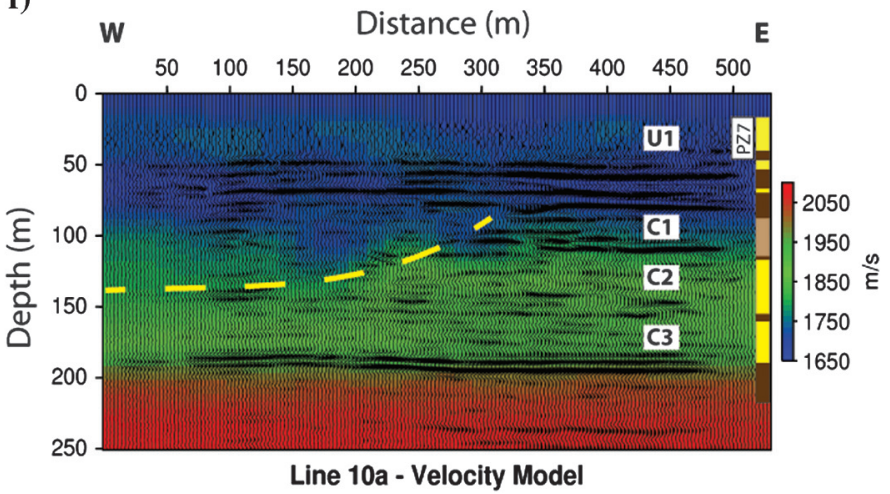

Figure 6. (a, c, and e) PSDM sections for line 5b, 8a, and 10a (Figure 1b). (b, d, and f) Interpreted PSDM sections overlain on final velocity models. Available well logs are overlain on lines $8 \mathrm{a}$ and 10a in panels (d and f), respectively. Well log colors correspond to yellow, sands/ gravels; brown, clays/silts; tan, clayey sand. U1 ranges in velocity from 1500 to $1600 \mathrm{~m} / \mathrm{s}$ on lines $5 \mathrm{~b}$ and $8 \mathrm{a}$. U1 has a higher velocity of $1700 \mathrm{~m} / \mathrm{s}$ on line 10a, which is located next to Lake Nokoué. Velocities within the confined aquifers increase gradually with depth, starting at $1700 \mathrm{~m} / \mathrm{s}$ in C1 and increasing to $1900 \mathrm{~m} / \mathrm{s}$ at the base of C3. The velocity jumps to $2100 \mathrm{~m} / \mathrm{s}$ across the interpreted clay/marl base. Note the good correlation of clay layers with reflections. Dashed lines highlight areas of interest discussed in the text. 
and F5bis. Lithology logs from the three wells are plotted on the seismic section for comparison.

The thickness and depth of the unconfined aquifer along this transect is highly variable. The thickness of the unconfined aquifer increases from an approximate $25-\mathrm{m}$ depth in the south to an approximate $50-\mathrm{m}$ depth in the north, evidenced by the package of reflections between 30- and 75-m depth on the southern half of the profile pinching out to a single reflection at an approximate 50-m depth on the northern half of the profile. This interpretation is further supported by the well $\operatorname{logs}$ and the lateral velocity decrease of approximately $300 \mathrm{~m} / \mathrm{s}$ from south to north. This velocity decrease correlates with the transition from clay to sand in wells F5bis and F4bis, respectively.

Definitive identification of aquifers $\mathrm{C} 1, \mathrm{C} 2$, and C3 is not possible across the transect due to the lack of reflections on the northern half of the profile between a 60- and 200-m depth (yellow dashed circle in Figure 6d). Most notably, the strong reflection at the 125-m depth, identified as clay in wells F4bis and F5bis on the southern half of the profile, is truncated at $600 \mathrm{~m}$ along the line. We interpret this to mean that aquifers $\mathrm{C} 1, \mathrm{C} 2$, and $\mathrm{C} 3$ are connected in this region due to the absence of confining clay layers. Note that the absence of confining clay layers would not be predicted by the well logs due to the lack of depth penetration by well F13 (Figure 6d). One important point to note is that we lack dense ray coverage in this area for our velocity inversion due to the absence of reflectors. Therefore, the velocity in this region is not well constrained. Despite this issue, we believe our interpretation to be valid given the high quality of the data and that, in these sediments, large acoustic velocity variations are unlikely.

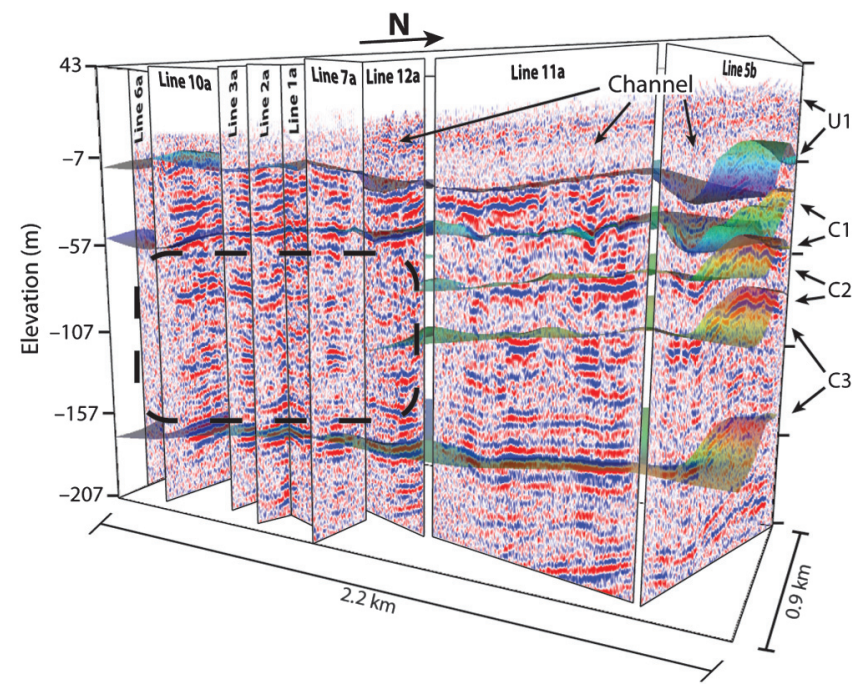

Figure 7. Depth-converted profiles of the nine lines closest to Lake Nokoué. The view is looking to the southwest from the northeast corner of the well field (Figure 1b). Colored surfaces indicate interpreted transitions between sand aquifers and confining clays. The two shallowest colored surfaces indicate the top and bottom of the shallowest confining clay layer, and the two middle colored surfaces indicate the tops of the second and third confining clay layers. The deepest colored surface indicates the top of the clay/marl base. The dashed black box highlights the area of laterally discontinuous confining clay layers beneath the southern portion of the lake shore. There is a shallow zone on the most northerly profiles (identified with arrows on lines 5b, 11a, and 12a) in which there is an absence of prominent reflectors seen on the southerly lines, which we interpret as a paleochannel.

\section{Line 10a}

Line 10a (Figure 6e and 6f) runs approximately perpendicular to the lake shore with piezometer PZ7 located on the eastern end of the line. PZ7 is approximately $200 \mathrm{~m}$ deep, and the lithologic log is plotted on the seismic section for comparison. Based on the well $\log$, the package of reflections between 50- and 110-m depth originates from the interbedded clays and clayey sands. This package of reflections is cut between 75- and 150-m depth on the western portion of the profile by what we interpret as an erosional channel (yellow dashed line in Figure 6f). Our interpretation is supported by the lateral velocity contrast between the interpreted erosional channel and aquifers $\mathrm{C} 1$ and $\mathrm{C} 2$ (Figure 6f).

\section{Lake lines}

The lateral continuity of the confining layers beneath the southern portion of the lake shore is highly variable between the interpreted clay layer at $-57 \mathrm{~m}$ elevation and the clay/marl base at $-157 \mathrm{~m}$ elevation (Figure 7). The four aquifer units (U1, C1, C2, C3) are easily identified along lines 5b and 11a. South of line 11a, the confining clay layers become less distinct and the confined aquifers $(\mathrm{C} 1, \mathrm{C} 2, \mathrm{C} 3)$ are difficult to confidently distinguish.

There is a shallow zone on the most northerly profiles (identified with arrows on lines 5b, 11a, and 12a in Figure 7) in which there is an absence of prominent reflectors seen on the southerly lines, which we interpret as the continuation of the western channel feature seen on line $5 \mathrm{~b}$ (Figure $6 \mathrm{~b}$ ). The axis of the channel is oriented slightly southeast-northwest, running from Lake Nokoué through the northern portion of the Godomey well field.

\section{DISCUSSION}

The lines closest to the lake and line 8 a show abrupt discontinuities in confining clay layers suggesting aquifers $\mathrm{C} 1, \mathrm{C} 2$, and $\mathrm{C} 3$ are connected beneath the southern portion of the lake shore as well as further inland. Our findings are supported by hydrologic data indicating the confinement of aquifers in this region is not complete (Figure 8). Figure 8 shows relative water levels in two piezometers

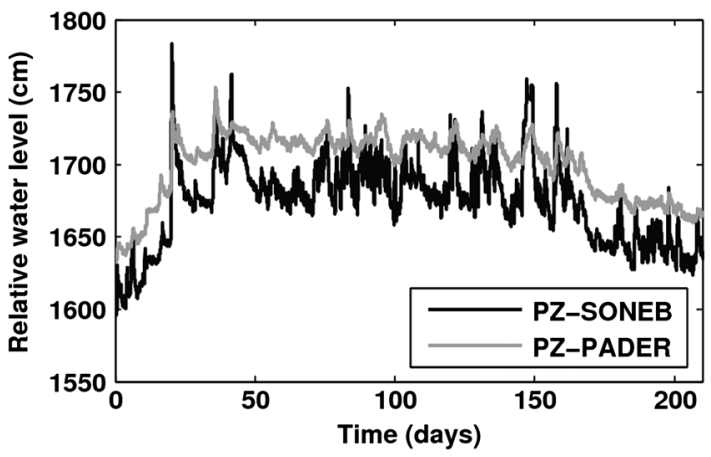

Figure 8. Relative water levels in piezometers PZ-SONEB (black) and PZ-PADER (gray) for a period of 210 days. The piezometers are located approximately $1.3 \mathrm{~km}$ apart (Figure $1 \mathrm{~b}$ ). PZ-SONEB is screened between 75- and 90-m depth, and PZ-PADER is screened between 165- and 180-m depth. Because the baseline for the water level is arbitrary, we added $400 \mathrm{~cm}$ to the PZ-SONEB data for easier comparison with the PZ-PADER data. The aquifers between 75and $90-\mathrm{m}$ and $165-180-\mathrm{m}$ depth respond to variations in pumping pressure simultaneously, indicating that aquifer confinement is not complete in this region and the aquifers are hydraulically connected. 
screened at different depths and located approximately $1.3 \mathrm{~km}$ from each other. The shallow aquifers $(\mathrm{C} 1, \mathrm{C} 2)$ and the deep aquifer $(\mathrm{C} 3)$ respond to variations in pumping pressure simultaneously, indicating that the aquifers are hydraulically connected in this region.

Erosional channels are present on lines 5b, 11a, 12a, and 10a near the lake shore. The northern channel (lines 5b, 11a, 12a) appears to be cutting through the shallow package of clays and clayey sands. We interpret the channel to be filled with saturated sands based on velocity estimates and well logs. Paleochannels filled with high-permeability material, such as unconsolidated sand, could provide preferential flow paths for saline water from Lake Nokoué to the Godomey well field.

\section{CONCLUSIONS}

Seismic reflection profiles from the Godomey well field show the subsurface lithology to be a complex system of discontinuous strata with variable thickness. The current hydrologic model assumes a series of continuous sand, silt, and clay layers with little variability along dip. The model layers form continuous sand aquifers separated by confining clay layers. The seismic data prove these model assumptions to be invalid. The confining layers in the aquifer system are not laterally continuous, and therefore they do not fully confine the sand aquifers in many areas of the Godomey well field. Additionally, there appear to be multiple locations of connectivity between confined aquifers due to the presence of erosional channels. These channels could be acting as preferential flow paths for saltwater between Lake Nokoué and the Godomey well field. The seismic profiles in the vicinity of the existing well records enable us to correlate and extrapolate lithologies beyond the single data point at each well location. This information can be integrated into the current hydrologic model to better constrain the geometry of the Godomey aquifer and improve model accuracy.

\section{ACKNOWLEDGMENTS}

Geoscientists Without Borders provided funding for this project. The authors thank D. Mikesell of the Massachusetts Institute of Technology, T. Blum of ETH Zurich, and E. Babcock of Boise State University. The authors also thank the students from l'Université Nice Sophia Antipolis and Université d'Abomey-Calavi for their help with data acquisition. Finally, we thank three anonymous reviewers for suggestions that greatly improved this manuscript.

\section{REFERENCES}

Barthel, R., B. G. J. S. J. Jagelke, J. Gotzinger, T. Gaiser, and A. Printz, 2008, Aspects of choosing appropriate concepts for modeling groundwater resources in regional integrated water resources management Examples from the Neckar (Germany) and Oueme catchment (Bénin):
Physics and Chemistry of the Earth, 33, 92-114, doi: 10.1016/j.pce .2007.04.013.

Barthel, R., B. G. J. S. Sonneveld, J. Gotzinger, M. A. Keyzer, S. Pande, A. Printz, and T. Gaiser, 2009, Integrated assessment of groundwater resources in the Oueme basin, Bénin, West Africa: Physics and Chemistry of the Earth, 34, 236-250, doi: 10.1016/j.pce.2008.04.001.

Blivi, A., E. J. Anthony, and L. M. Oyede, 2002, Sand barrier development in the Bight of Bénin, West Africa: Ocean and coastal management, 45, 185-200, doi: 10.1016/S0964-5691(02)00054-6.

Boukari, M., P. Viaene, and F. Azonsi, 2008, Three-dimensional modeling of a coastal sedimentary basin of southern Bénin (West Africa), in S. Adelana, and A. MacDonald, eds., Applied groundwater studies in Africa: International Association of Hydrogeologists, Selected Papers on Hydrogeology, vol. 13, 437-456.

Bradford, J. H., 2002, Depth characterization of shallow aquifers with seismic reflection, Part I - The failure of NMO velocity analysis and quantitative error prediction: Geophysics, 67, 89-97, doi: 10.1190/1.1451362.

Bradford, J. H., L. Liberty, M. Lyle, W. Clement, and S. Hess, 2006, Imaging complex structure in shallow seismic-reflection data using prestack depth migration: Geophysics, 71, no. 6, B174-B181, doi: 10.1190/1.2335659.

Bradford, J. H., and D. S. Sawyer, 2002, Depth characterization of shallow aquifers with seismic reflection, Part II - Prestack depth migration and field examples: Geophysics, 67, 98-109, doi: 10.1190/1.1451372.

Bray, B., F. T. C. Tsai, Y. Sim, and W. W. B. Yeh, 2007, Model development and calibration of a salt-water intrusion model in southern California: Journal of the American Water Resources Association, 43, 1329-1343, doi: $10.1111 / \mathrm{j} .1752-1688.2007 .00098 . x$.

Gazdag, J., 1978, Wave equation migration with the phase-shift method: Geophysics, 43, 1342-1351, doi: 10.1190/1.1440899.

Giustiniani, M., F. Accaino, S. Picotti, and U. Tinivella, 2009, 3D seismic data for shallow aquifers characterization: Journal of Applied Geophysics, 68, 394-403, doi: 10.1016/j.jappgeo.2009.03.005.

Guo, N., and S. Fagin, 2002a, Becoming effective velocity-model builders and depth imagers, Part 1 - The basics of prestack depth migration: The Leading Edge, 21, 1205-1209, doi: 10.1190/1.1536135.

Guo, N., and S. Fagin, 2002b, Becoming effective velocity-model builders and depth imagers, Part 2 - The basics of velocity-model building, examples and discussions: The Leading Edge, 21, 1210-1216, doi: 10.1190/ 1.1536136

Nguyen, F., A. Kemna, A. Antonsson, P. Engesgaard, O. Kuras, R. Ogilvy, J. Gisbert, S. Jorreto, and A. Pulido-Bosch, 2009, Characterization of seawater intrusion using 2D electrical imaging: Near Surface Geophysics, 7 377-390, doi: 10.3997/1873-0604.2009025.

Shtivelman, V., and M. Goldman, 2000, Integration of shallow reflection seismics and time domain electromagnetics for detailed study of the coastal aquifer in the Nitzanim area of Israel: Journal of Applied Geophysics, 44, 197-215, doi: 10.1016/S0926-9851(98)00053-6.

Silliman, S. E., B. I. Borum, M. Boukari, N. Yalo, S. Orou-Pete, D. McInnis, C. Fertenbaugh, and A. Mullen, 2010, Issues of sustainability of coasta groundwater resources: Bénin, West Africa: Sustainability, 2, 2652-2675, doi: $10.3390 /$ su2082652.

Silliman, S. E., M. Boukari, L. Lougbegnon, and F. Azonsi, 2011, Overview of a multifaceted research program in Bénin, West Africa: An international year of planet earth groundwater project, in J. Jones, and A. Anthony, eds., Sustaining groundwater resources: A critical element in the global water crisis, Springer, 175-186.

Stork, C., 1992, Reflection tomography in the postmigrated domain: Geophysics, 57, 680-692, doi: 10.1190/1.1443282.

Sumanovac, F., 2006, Mapping of thin sandy aquifers by using high resolution reflection seismic and 2-D electrical tomography: Journal of Applied Geophysics, 58, 144-157, doi: 10.1016/j.jappgeo.2005.06.005.

Vandenbohede, A., E. Van Houtte, and L. Lebbe, 2009, Sustainable groundwater extraction in coastal areas: A Belgian example: Environmental Geology, 57, 735-747, doi: 10.1007/s00254-008-1351-8.

Werner, A. D., 2010, A review of seawater intrusion and its management in Australia: Hydrogeology Journal, 18, 281-285, doi: 10.1007/s10040009-0465-8.

Yang, C. H., L. T. Tong, and C. F. Huang, 1999, Combined application of DC and TEM to sea-water intrusion mapping: Geophysics, $\mathbf{6 4}, 417-425$, doi: $10.1190 / 1.1444546$ 